\title{
Flexible Periods Allow for Combined Analytical and Laboratory Experiences Within an Introductory Mechanics Course
}

\section{Dr. Shawn P Gross, Villanova University}

Dr. Shawn P. Gross is an associate professor in the Department of Civil and Environmental Engineering at Villanova University. He has as M.S.E. and Ph.D. degrees in Civil Engineering from the University of Texas at Austin, and a B.S.E. degree from Tulane University. He teaches undergraduate and graduate courses on mechanics and structural design (reinforced concrete, structural steel, masonry, and wood).

\section{Prof. David W Dinehart, Villanova University}

Professor and Chairman Department of Civil and Environmental Engineering Villanova University 


\title{
Flexible Periods Allow for Combined Analytical and Laboratory Experiences Within an Introductory Mechanics Course
}

\begin{abstract}
In 2009, the Department of Civil \& Environmental Engineering at Villanova University reinvented its course sequence in undergraduate mechanics. Classic courses in Statics, Mechanics of Solids, and Civil Engineering Materials were restructured into a two-course sophomore-level sequence (Mechanics I and Mechanics II), and elements of Dynamics were integrated with Fluid Mechanics and the associated laboratory to form the junior-level course Mechanics III. These courses emphasize real-world applications and are taught using an integrated approach. For example, the first course intersperses topics traditionally covered in Statics (such as truss analysis) with topics typically addressed in Mechanics of Solids (such as stress-strain relationships and factor of safety) rather than covering all of the Statics content prior to Mechanics of Solids content. Using this approach, students are able to apply concepts to solve larger, complex, and more interesting problems much earlier in the curriculum.
\end{abstract}

The new courses are each worth four credit hours and are scheduled to meet four times a week, including three 50-minute sessions and one 165-minute flexible or "flex" period. The flex period is the cornerstone of the revised course structure, as it allows for several different teaching and learning strategies that would not be possible in the shorter periods. These periods are specifically designed to be active learning sessions, which allow for better integration of individual concepts to attain a higher level of application. While the 50-minute sessions involve short lectures and the solution of multiple stand-alone problems, several of the flex periods are used for combined analytical and laboratory-type experiences that extend far beyond simple single-concept problems similar to those found in most textbooks. Other uses of the flex period include computation-based overarching problems that involve a series of independent but complementary calculation steps to solve a larger problem, and comprehensive examinations.

This paper discusses how the flex periods are used in the Mechanics I course, and presents details on three of the combined analytical and laboratory-type experiences used during these periods. Specific learning outcomes for each exercise are identified. Student feedback from multiple years of student surveys is presented. Administrative considerations such as faculty time requirements, course section sizes, and laboratory costs are also discussed.

Introduction

The Department of Civil and Environmental Engineering (CEE) at Villanova University began offering its required mechanics sequence in a new integrated format to sophomores beginning with the Fall 2009 semester. As shown in Table 1, the classical sequence of coursework in subjects of Statics, Dynamics, Mechanics of Solids, Fluid Mechanics, and Civil Engineering Materials was replaced with a series of three four credit courses. An overview of this curriculum restructuring process is provided by Glynn et al. ${ }^{1}$ and Wadzuk et al. ${ }^{2}$ A Body of Knowledge (BOK) approach was used to identify the key concepts to be included in the three new courses. ${ }^{3}$ 
Table 1 - Old and new mechanics curricula in CEE at Villanova University

\begin{tabular}{|c|c|c|c|c|c|}
\hline \multicolumn{2}{|c|}{ Old Mechanics Curriculum } & \multicolumn{3}{c|}{ New Mechanics Curriculum } \\
\hline Course & $\begin{array}{c}\text { Credit } \\
\text { Hours }\end{array}$ & $\begin{array}{c}\text { Semester in } \\
\text { Curriculum }\end{array}$ & Course & $\begin{array}{c}\text { Credit } \\
\text { Hours }\end{array}$ & $\begin{array}{c}\text { Semester in } \\
\text { Curriculum }\end{array}$ \\
\hline $\begin{array}{c}\text { Mechanics: Statics } \\
\text { and Dynamics }\end{array}$ & 4 & $\begin{array}{c}\text { Sophomore } \\
\text { Fall }\end{array}$ & $\begin{array}{c}\text { Mechanics } \\
\text { I }\end{array}$ & 4 & Sophomore Fall \\
\hline Mechanics of Solids & 3 & $\begin{array}{c}\text { Sophomore } \\
\text { Spring }\end{array}$ & $\begin{array}{c}\text { Mechanics } \\
\text { II }\end{array}$ & 4 & Sophomore Spring \\
\hline $\begin{array}{c}\text { Civil Engineering } \\
\text { Materials }\end{array}$ & 2 & Junior Fall & $\begin{array}{c}\text { Mechanics } \\
\text { III }\end{array}$ & 4 & Junior Fall \\
\cline { 1 - 2 } Fluid Mechanics & 3 & Junior Fall & & & \\
\cline { 1 - 2 } Fluid Mechanics \\
Lab
\end{tabular}

Table 2 - Details of new mechanics curriculum (Mechanics I, II, and III)

\begin{tabular}{|c|c|c|c|l|}
\hline Course & Course Title & $\begin{array}{c}\text { Credit } \\
\text { Hours }\end{array}$ & $\begin{array}{c}\text { Semester in } \\
\text { Curriculum }\end{array}$ & \multicolumn{1}{c|}{ Description } \\
\hline CEE & $\begin{array}{c}\text { Mechanics I: } \\
\text { Fundamental } \\
\text { Behavior }\end{array}$ & 4 & $\begin{array}{c}\text { Sophomore } \\
\text { Fall }\end{array}$ & $\begin{array}{l}\text { Forces and moments; equilibrium of } \\
\text { particles and rigid bodies; analysis of } \\
\text { trusses; stress and strain; axial } \\
\text { deformations; distributed force patterns; } \\
\text { centroids and moments of inertia; dry } \\
\text { friction; column buckling. }\end{array}$ \\
\hline CEE & $\begin{array}{c}\text { Mechanics II: } \\
\text { Material } \\
\text { Behavior }\end{array}$ & 4 & Sophomore \\
& Spring & $\begin{array}{l}\text { Shear and moment diagrams; bending } \\
\text { and shear stresses; beam deflections; } \\
\text { torsion; stress and strain } \\
\text { transformations; combined loadings; } \\
\text { characteristics of civil engineering } \\
\text { materials including Portland cement } \\
\text { concrete, masonry, wood, composites, } \\
\text { and asphalt; experimental testing using } \\
\text { recognized standards. }\end{array}$ \\
\hline CEE & $\begin{array}{l}\text { Mechanics III: } \\
\text { Fluid Behavior }\end{array}$ & 4 & Junior Fall & $\begin{array}{l}\text { Fluid properties; kinematics of particles } \\
\text { and flow; conservation of mass, energy } \\
\text { and momentum; fluid resistance, } \\
\text { boundary layer theory, flow in conduits; } \\
\text { lift and drag; turbomachines. }\end{array}$ \\
\hline
\end{tabular}

The resulting three courses are summarized in Table 2. Mechanics I covers traditional concepts of Statics and Mechanics of Solids with emphasis on axial loading. Basic material properties and linear elastic materials such as steels are also included. Mechanics II consists of remaining concepts from Statics and Mechanics of Solids, and introduces more complex civil engineering 
materials such as concrete, composites, wood, and asphalt, while Mechanics III focuses on concepts from Fluid Mechanics, Fluids Mechanics Lab, and particle Dynamics.

The three courses are taken beginning with the first semester (Fall) of the sophomore year. The average section size is about 30 students, with a maximum of 35 . All three courses are teamtaught by a pair of faculty members and utilize a four meeting per week format, in which there are three 50-minute periods (Monday, Wednesday, and Friday). Mechanics I was converted to an inverted or "flipped" format in 2013, and Mechanics II was converted to the same format in 2015. In the inverted format the students are responsible for viewing the lectures as homework outside of the class. Consequently, the 50-minute periods in Mechanics I and II are primarily used for interactive problem solving sessions. Neither Mechanics I nor Mechanics II requires an outside textbook, and instead students purchase a course binder with all lecture notes and all inclass and out-of-class problems that will be solved for the semester. Mechanics III is currently taught in a more traditional format, with lectures delivered during class.

All three courses have a fourth period that is a 165-minute "flexible" period that meets on off days, and is used for other types of active learning sessions (laboratories, design exercises, overarching problems) and exams. Additional detail will be provided herein on the structure and content of the "flex" periods for Mechanics I.

\section{Literature Review}

In the past twenty years there has been a pedagogical shift towards problem based learning, the incorporation of concept oriented examples, and the use of interactive learning activities within undergraduate engineering, science, and medical school curricula ${ }^{4-7}$. Assessments have demonstrated $^{8-11}$ that students generally learn better when taught in these environments. Consequently, these initiatives have been adopted by many engineering programs. ${ }^{12-14}$ Many ambitious faculty members have implemented problem based learning within individual courses, while some departments and colleges have incorporated the philosophy systemically throughout entire programs. $^{15-17}$

When Florida Gulf Coast University launched Bachelor of Science degree programs in bioengineering, environmental engineering and civil engineering, an interdisciplinary engineering curriculum including eight common courses, one each semester, for all engineering majors was utilized. Engineering Mechanics was the third course in the sequence. The course is a combined, four credit course on statics and dynamics taught in a combined lecture-lab format. The format of the course involves two 150-minute meetings twice a week. The extended meeting periods lend themselves particularly well to a lecture-lab format. Class time was used for handson activities in small groups. These activities include aspects of active and cooperative learning for learning problem solving techniques, with instruction and guidance from the instructor during the learning process. These longer periods allowed for the instructor to focus on interdisciplinary problems rather than traditional civil and mechanical engineering problems. The authors provide a list of supplies and required equipment. ${ }^{18}$ Hall et al. ${ }^{19}$ also outline the design, construction, and fabrication of seven laboratory exercises and a design project for a sophomore level integrated statics and mechanics of materials course. Each laboratory and project is detailed, including photographs, drawings of the equipment, student work requirements, principles 
demonstrated, and equipment design and fabrication. The authors highlight their experiences and present addition activities to improve student learning.

Kaul and Sitaram ${ }^{20}$, present a combined course in Statics and Dynamics with many new features that are not observed in the traditional courses. This course has added new learning outcomes to accommodate laboratory experiences. The course has been designed for four credit hours consisting of 180 minutes of lecture time, 120 minutes of laboratory time and 60 minutes of tutoring time every week of the fourteen-week semester. The contact time has been distributed so as to promote scaffolding of the learning process. The learning outcomes established for this course include ABET1 outcomes 'a' and 'e' as well as ABET1 outcomes 'b' and 'k'. Details of the curriculum are provided. Dodge et al..$^{21}$ present hands-on experiences for teaching topics relevant to statics, mechanics of materials and structural analysis. The author use structural engineering as the specific discipline and actual beams, trusses and frames as the specific tools to achieve this teaching objective. The students can see the structures being discussed in lecture and manipulate the loads, constraints and materials in the process for themselves. Campbell ${ }^{22}$ takes the hands-on work further as he presents an approach to engineering educational instruction that utilizes experiential learning through the making and breaking of structural models in a freshman Engineering Statics course. During testing in front of the assembled class, the instructor has an opportunity to utilize the varied failure modes exhibited by the student models, as a real-time teaching and learning experience. Course structure and relevant assessment tasks for students are presented.

\section{Structure of "Flex" Periods}

The Mechanics I course at Villanova University meets four days each week of the semester. Three of the meetings (Monday, Wednesday, and Friday) are 50-minute classroom periods while the fourth (typically on a Thursday) is a 165-minute long "flex" period that is used for a variety of learning exercises and activities. The extended length of this class meeting allows for the use of different teaching and learning strategies that would not work well in a 50-minute period.

Table 3 lists the fourteen flex period exercises for the entire semester of Mechanics I, and outlines the type of learning activity and topics addressed by that activity. These periods all involve some form of active learning, and most integrate several otherwise stand-alone mechanics concepts in an applied fashion. Some periods involve multi-step calculation-based problems called "overarching" problems ${ }^{23}$ that bring together many isolated computations in an integrated fashion on a single problem. Other periods involve laboratory tests or small testing of scale models in the classroom. Some periods are used for combined analytical and laboratory experiences where students compute a "calculated" answer and are able to compare it to a "tested" answer, or where students collect data and manipulate it with common mechanics calculations to determine an experimental parameter.

Depending on the nature of the flex period, the class may meet in the regular classroom or another facility such as a specialized classroom intended to facilitate group work, or a department laboratory. Depending on the activity, students may work individually or more frequently, in groups of varying sizes. 
Table 3 - Flex Period Schedule for Semester

\begin{tabular}{|c|c|l|l|}
\hline $\begin{array}{c}\text { Flex } \\
\text { Period } \\
\#\end{array}$ & $\begin{array}{c}\text { Meeting } \\
\#^{\text {a }}\end{array}$ & \multicolumn{1}{|c|}{ Exercise/Activity } & \multicolumn{1}{|c|}{ Topic(s) } \\
\hline 1 & 3 & $\begin{array}{l}\text { Small group work including simple } \\
\text { measurements and calculations }\end{array}$ & $\begin{array}{l}\text { Engineering Measurements and } \\
\text { Calculations }\end{array}$ \\
\hline 2 & 7 & $\begin{array}{l}\text { Problem solving including small group } \\
\text { design problem and small-scale } \\
\text { "prototype” testing }\end{array}$ & $\begin{array}{l}\text { Particle Equilibrium / } \\
\text { Introduction to Design }\end{array}$ \\
\hline 3 & 10 & $\begin{array}{l}\text { Problem solving (several small } \\
\text { problems) and lecture to introduce } \\
\text { Overarching problem \#1 }\end{array}$ & $\begin{array}{l}\text { Rigid Body Equilibrium / } \\
\text { Introduction to Trusses }\end{array}$ \\
\hline 4 & 14 & $\begin{array}{l}\text { Complex analysis problem and } \\
\text { experimental (laboratory) verification of } \\
\text { results (open-web steel joist) }\end{array}$ & $\begin{array}{l}\text { Truss Analysis / Stress / Factor } \\
\text { of Safety / Capacity Analysis of } \\
\text { Multicomponent Systems }\end{array}$ \\
\hline 5 & 21 & $\begin{array}{l}\text { Examination \#1 } \\
\text { Two laboratory experiments conducted } \\
\text { in small groups }\end{array}$ & $\begin{array}{l}\text { Stress-Strain Relationships / } \\
\text { Material Properties of Steel }\end{array}$ \\
\hline 6 & 25 & $\begin{array}{l}\text { Overarching problem \#1 (multistep } \\
\text { problem on steel truss bridge addressing } \\
\text { many integrated mechanics concepts) }\end{array}$ & Numerous \\
\hline 7 & 29 & $\begin{array}{l}\text { Experimental determination of } \\
\text { coefficients of static and kinetic friction } \\
\text { in laboratory }\end{array}$ & $\begin{array}{l}\text { Coefficients of Friction / Rigid } \\
\text { Body Equilibrium / Laws of } \\
\text { Motion / Design of Experiments }\end{array}$ \\
\hline 14 & 53 & $\begin{array}{l}\text { Examination \#2 } \\
\text { Problem solving (two analysis problems } \\
\text { involving fluid pressure on straight and } \\
\text { curved surfaces) }\end{array}$ & $\begin{array}{l}\text { Distributed Loading / Centroids } \\
\text { and Centers of Gravity }\end{array}$ \\
\hline 11 & 40 & $\begin{array}{l}\text { Overarching problem \#2 (multistep } \\
\text { problem on concrete gravity dam } \\
\text { addressing many integrated mechanics } \\
\text { concepts) }\end{array}$ & Numerous \\
\hline 13 & 48 & $\begin{array}{l}\text { Examination \#3 } \\
\text { Overarching problem \#3 (multistep } \\
\text { problem on water tower column design } \\
\text { addressing many integrated mechanics } \\
\text { concepts) }\end{array}$ & Numerous \\
\hline 56 class meetings totird World Country \\
numerical meeting \#. including 3 exams during the semester. Exams are not identified by a \\
\hline
\end{tabular}




\section{Learning Outcomes}

Three specific flex periods are discussed in detail in the remainder of this paper, to illustrate the types of learning experiences that can be implemented with this extended class meeting time. Learning outcomes are announced to students at the beginning of each lecture and are provided on the first PowerPoint slide of the notes associated with that lecture. The specific learning outcomes associated with the three periods discussed in detail are identified in Table 4.

Table 4 - Specific Learning Outcomes for Three Flex Periods Discussed in This Paper

\begin{tabular}{|c|c|c|}
\hline $\begin{array}{l}\text { Flex } \\
\text { Period } \\
\quad \#\end{array}$ & $\begin{array}{c}\text { Meeting } \\
\#\end{array}$ & Learning Outcomes \\
\hline 2 & 7 & $\begin{array}{l}\text { - } \text { Solve for unknowns in a 2-D particle equilibrium problem. } \\
\text { - } \quad \text { Explain the difference between analysis and design. } \\
\text { - } \quad \text { Define factor of safety. }\end{array}$ \\
\hline 4 & 14 & $\begin{array}{l}\text { - } \quad \text { Identify key components of an open web steel joist. } \\
\text { - } \quad \text { Solve for unknown forces in a truss using the method of joints. } \\
\text { - } \quad \text { Solve for unknown forces in a truss using the method of sections. } \\
\text { - } \quad \text { Calculate the average normal stress acting on a cross-section. } \\
\text { - } \quad \text { Predict the maximum design capacity and failure load of a simple } \\
\text { structure given allowable stresses and factors of safety. }\end{array}$ \\
\hline 8 & 29 & $\begin{array}{l}\text { - Determine whether or not an object remains in static equilibrium } \\
\text { under a given set of loads. } \\
\text { - Determine kinematic properties (acceleration, velocity, distance, or } \\
\text { time) for a particle or system of particles using the equations of } \\
\text { motion in rectangular coordinates. } \\
\text { - Design a simple experiment to determine unknown quantities. }\end{array}$ \\
\hline
\end{tabular}

Flex Period \#2: Particle Equilibrium and Factor of Safety

In the second flex period meeting of the semester, students have a hybrid class period that involves three problems related to two-dimensional particle equilibrium. The first two problems are fairly straightforward and are solved individually by students with faculty leading a structured solution methodology at the front of the classroom. Since these two problems require about 50 minutes to solve, the first third of the flex period is actually very similar to a typical non-flex period in the course.

For the remainder of the flex period, students work on a simple group exercise that introduces the concepts of design and factor of safety. Students are given a scenario in which their group is to act as a design firm that is responsible for designing a system of two cables to support a machine in preparation for cleaning at an industrial plant. The weight of the machine is specified and the geometry of the cables is given, as shown in the simple sketch in Figure 1. Students are also given a table of five cable choices with varying capacities and costs, which can also be seen in Figure 1. 


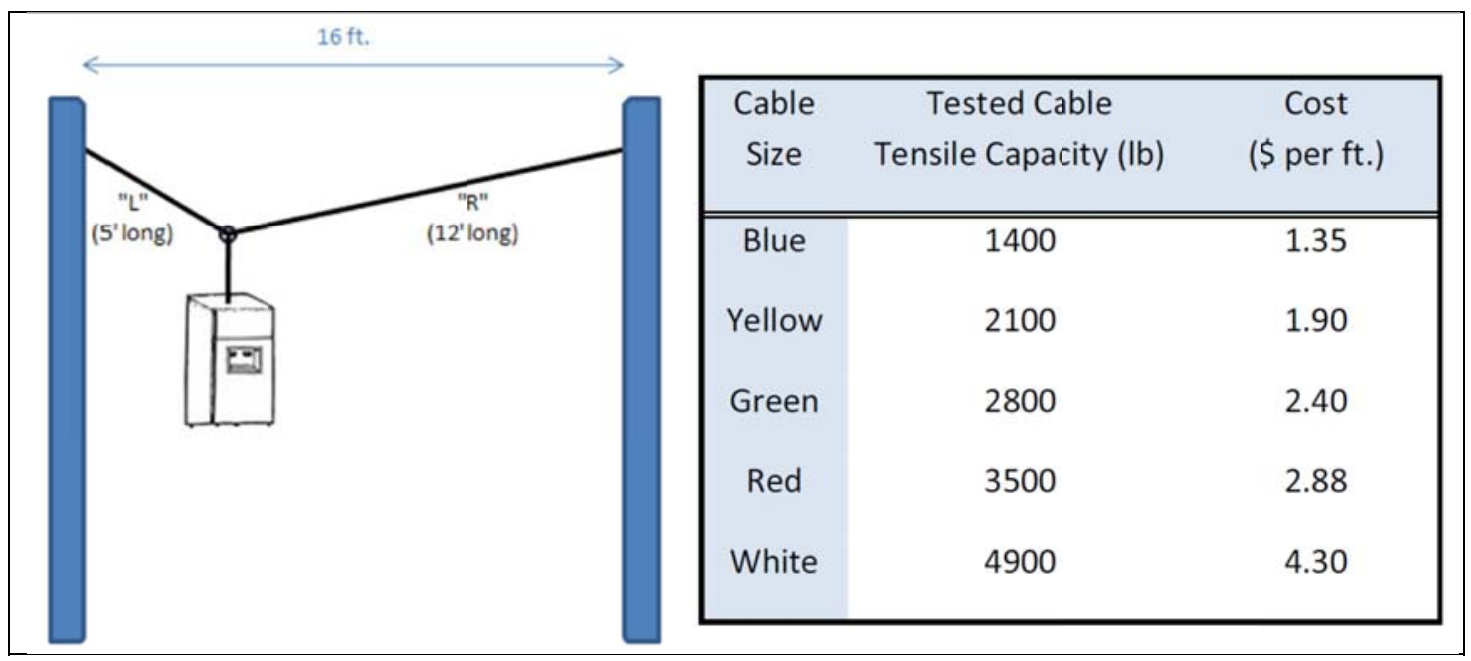

Figure 1 - Cable layout and capacity for introduction to design and factor of safety exercise

In the problem statement, students are given the instructions to select a cable size (color designation) for each of the two cables and provide complete calculations. They are also told that they should be prepared to test a scale model of the cables after all groups have completed their calculations by selecting appropriate fishing line wires from the selections at the front of the room. Students are given no other instructions but given the nature of the calculations that they have been doing in the previous class period and earlier in the flex period, they easily compute the forces in the cables for the given machine weight and then their group goes about selecting cables. For the given machine weight of $1100 \mathrm{lb}$, it can easily be shown that the cable on the left has $1560 \mathrm{lb}$ of force and the cable on the right has $1370 \mathrm{lb}$.

Most student groups tend to look at the table of cable choices and their calculated forces and instinctively choose what appears to be the most economically acceptable size for each cable, although they have been given no economic constraints in the problem. They will typically choose Yellow (2100 lb “capacity”) for the left cable and Blue (1400 lb "capacity”) for the right cable. Occasionally, a student group will have a good discussion about "being safe" or "being conservative" and may consider choosing a more expensive, stronger pair of cables. In their quest for the "right answer", these groups will sometimes ask the instructors for guidance on this choice, but the instructors refuse to provide any additional information not contained in the problem statement. The students must choose their design cable combination entirely on their own.

After all student groups have made their selections, the instructors recap the selected choices for the class as a whole More than 90 percent of the groups have historically chosen the YellowBlue combination mentioned in the previous paragraph. The instructors then tell the students it is time to test the cables, but first stop the class and distribute a few cans of Play-Doh to each group. The students are given five minutes to make a figure of "something or someone that is important to you” using the clay. Students have fun and might make a model of a loved one, a pet, a professor, or items such as pizza and french fries. After this, the groups are called up and instructed to place their models at the bottom of the loading rig shown in Figure 2. A starting weight of about six pounds is hung from the cables, and weight is slowly added in $1 / 2$ pound increments until one of the wires snaps. 


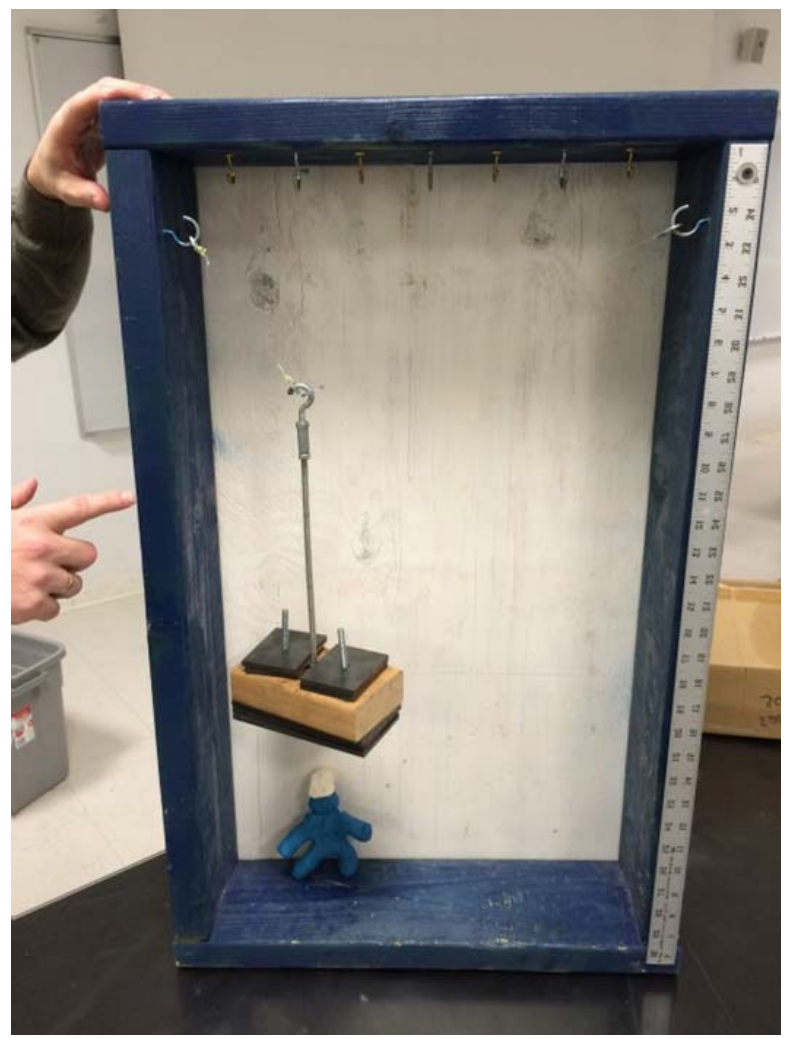

Figure 2 - Loading rig for fishing line exercise

The numerical values for the entire exercise have been rigged (pun intended) to lead to a situation where if the Yellow-Blue combination is chosen, there is a roughly 50-50 chance that the scaled weight of $11 \mathrm{lb}$ can be held without failure. A number of Yellow-Blue wire combinations are tested to failure to illustrate variability of results. When the wires fail, especially at loads below the $11 \mathrm{lb}$ threshold, the entire class lets out a big laugh, moan, or gasp as the Play-Doh figures they made are crushed. Students get the obvious takeaway that they must include a safety margin to increase the level of confidence in the desired outcome. A more conservative design, such as a Red-Green combination that is based on a factor of safety of 2 for each cable, is always tested to reinforce the point.

After the testing has been completed, the instructors try to coalesce the learning by providing a short 15 minute lecture that formally introduces the term factor of safety. Students are instructed to re-read the table of values in the problem and the vague term "Tested Cable Tensile Capacity" is discussed. Common factors of safety used across a range of engineering disciplines are discussed, and along with how the repercussions of failure differ for different designs.

The entire exercise, including group work on the calculations, construction of the Play-Doh figures, testing of cables, and short lecture recap, takes about 90 minutes of class time. Through a simple exercise, students develop a tangible understanding of the concepts of factor of safety and basic design. 
Flex Period \#4: Analysis and Testing of an Open-Web Steel Joist

During the fourth flex period meeting of the semester, students conduct their first comprehensive capacity analysis of a system made up of several (i.e. more than two) components, and then later during the same 165-minute period students test that system in the laboratory to determine its tested capacity. In particular, students analyze an open-web steel joist like those used in many roof systems, as shown in Figure 3.

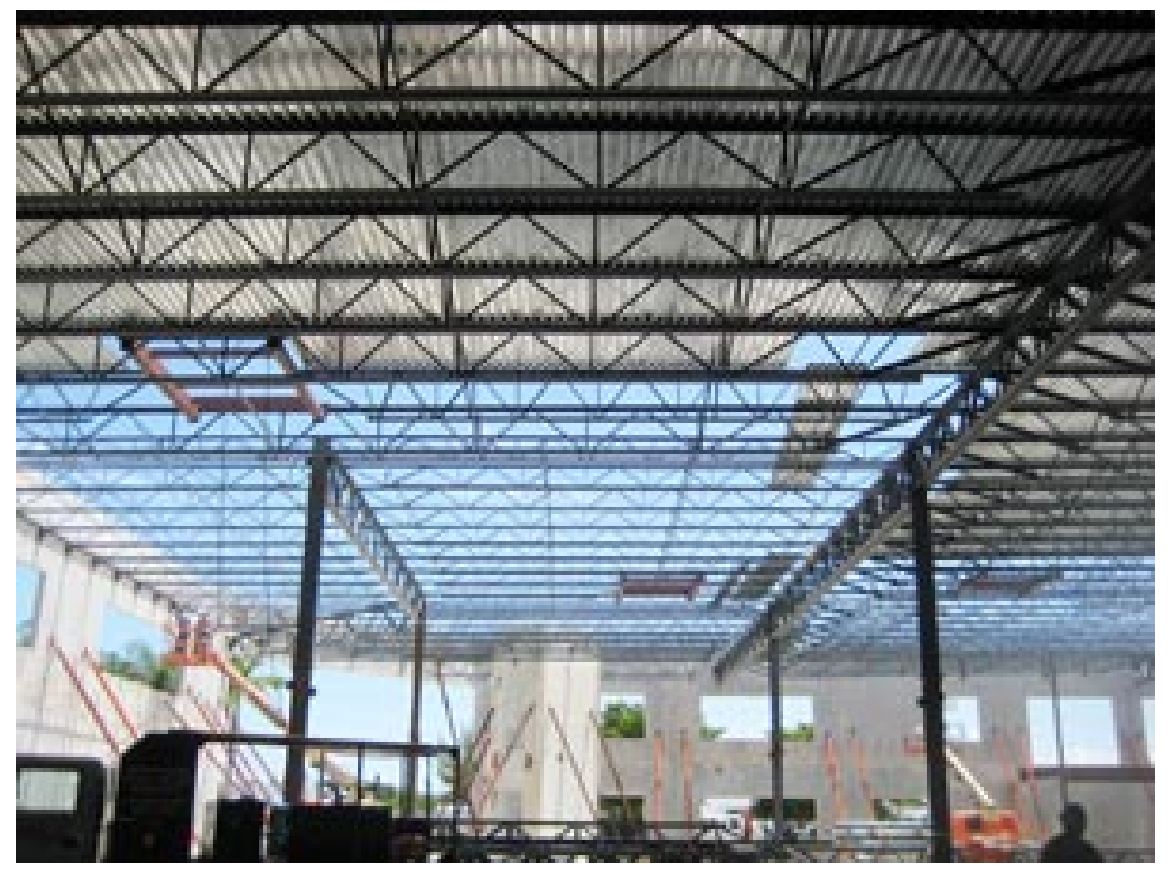

Figure 3 - Typical Open-Web Steel Joist Used in a Roof System (Courtesy: Steel Joist Institute http://steeljoist .org)

In the class periods leading up to this exercise, students learn the fundamentals of particle and rigid body equilibrium for simple two-dimensional objects. They then apply these concepts of equilibrium and free body diagrams using the method of joints and method of sections analysis techniques for trusses. Students also learn about factor of safety and the differences between analysis and design, and the basic concepts of normal (axial) stress. All of these concepts are integrated into this flex period exercise.

At the beginning of the period, the instructors present a brief background on open-web steel joists, show photos of joist roof collapses, introduce the joist to be analyzed during the period, and lead a short discussion on approximations that are used in the analysis. The instructors present the PowerPoint slides shown in Figure 4 to discuss these approximations and their impacts. Students analyze the joist as if it is a true truss made up of pin-connected members knowing that all of the joints are actually welded. Additionally, while joists are most commonly loaded by uniformly distributed loading patterns, the students are instructed to use the simplification of equivalent joint loading. Later in the laboratory, students are able to see the joints and loading arrangement up close and this discussion is extended. 
A schematic model of the joist that is analyzed and tested can be seen in Figure 5. The joist was designed specifically for this exercise and is approximately $16 \mathrm{ft}$. in length and $18 \mathrm{in}$. in depth. The joist has 23 members and is symmetric. A set of these joists were donated to Villanova University by New Millennium Building Systems, one of the nation's largest joist manufacturing companies, for use in this educational exercise. A large enough quantity of joists was provided to facilitate the implementation of this exercise in several years' worth of classes without major variation in the tested results.

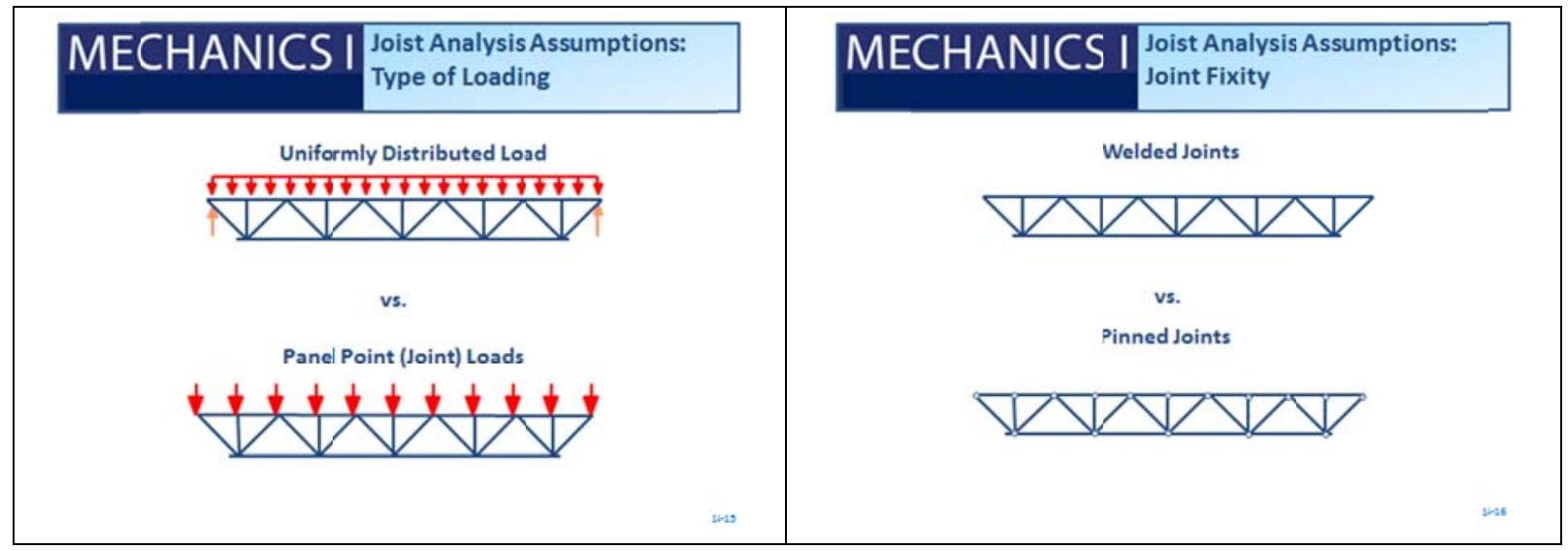

Figure 4 - PowerPoint slides used to discuss analysis simplifications to be used by students

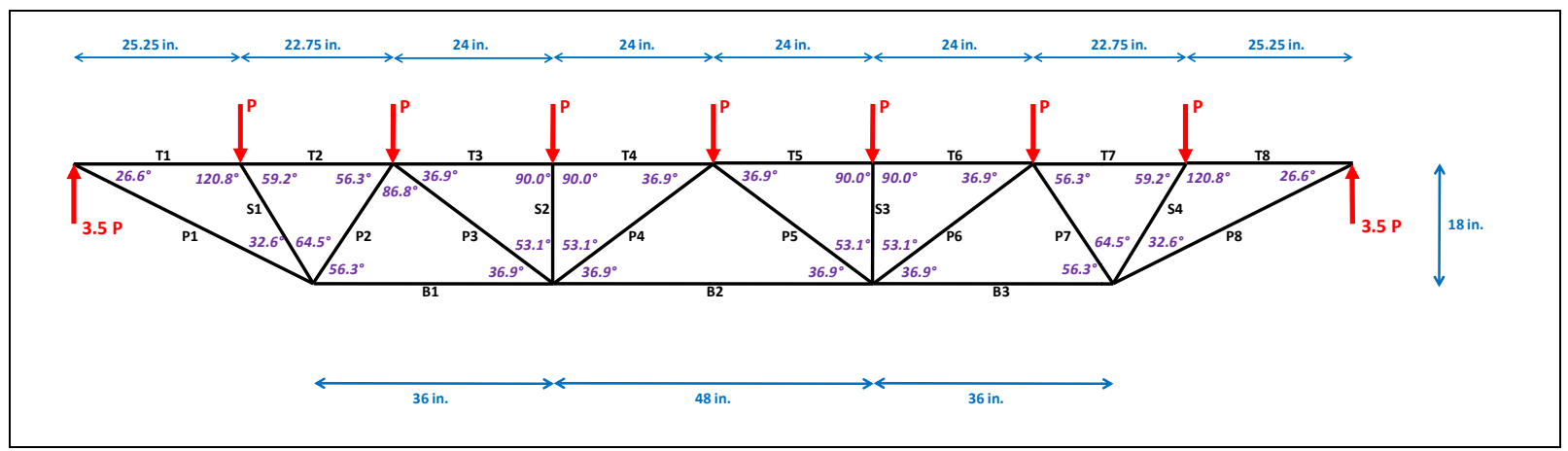

Figure 5 - Truss model used for analysis of joist capacity by students

Students must turn in the assignment individually but are permitted to work together during the calculation period in small groups. A classroom designed specifically for this type of group work is used, as shown in Figures 6 and 7. The assignment itself is designed to guide students through a system-level analysis involving many members for the first time. For example, in order to predict the capacity of the joist, students must first be able to determine the relative forces (stress) present in the members for an arbitrary set of applied loads, determine the capacity of each individual member (top chord, bottom chord, or web), and identify which member "governs" the design capacity (including factor of safety) or nominal capacity.

Students perform the entire analysis for a unit loading (1 kip per top chord joint). Specific calculation steps that students follow are identified in Table 5. For each calculation step, the students must answer a pair of questions that relate to that step. During the period, the instructors project the spreadsheet-based table of numerical answers shown in Figure 8 onto the 
screen at the front of the classroom. Answers are gradually revealed during the period to keep students on pace, and the instructors answer student questions as they arise. At the conclusion of the calculation period, the instructors spend about 15 minutes emphasizing the key concepts, including the difference between members with the highest forces, those with the highest stresses, those that govern the design based on allowable stress limits, and those that are expected to fail first. The spreadsheet-based table is also used to emphasize how (for a linear system) the unit load can be scaled up to change numerical values proportionally without changing which members have the maximum force, stress, or stress ratio.

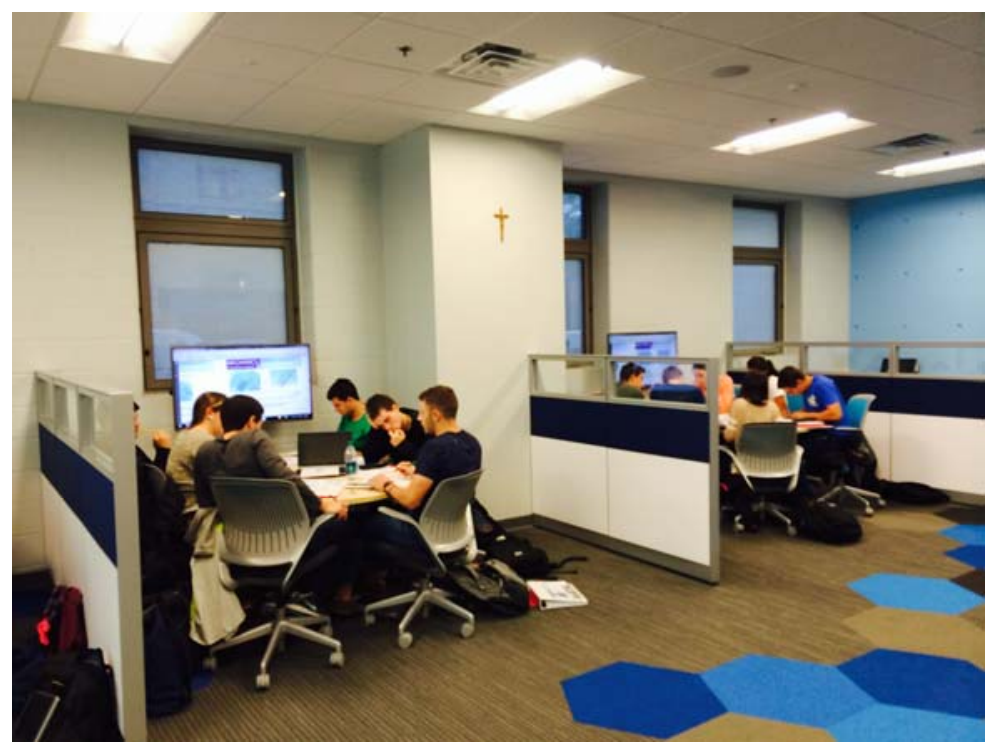

Figure 6 - Classroom Designed for Interactive Group Learning

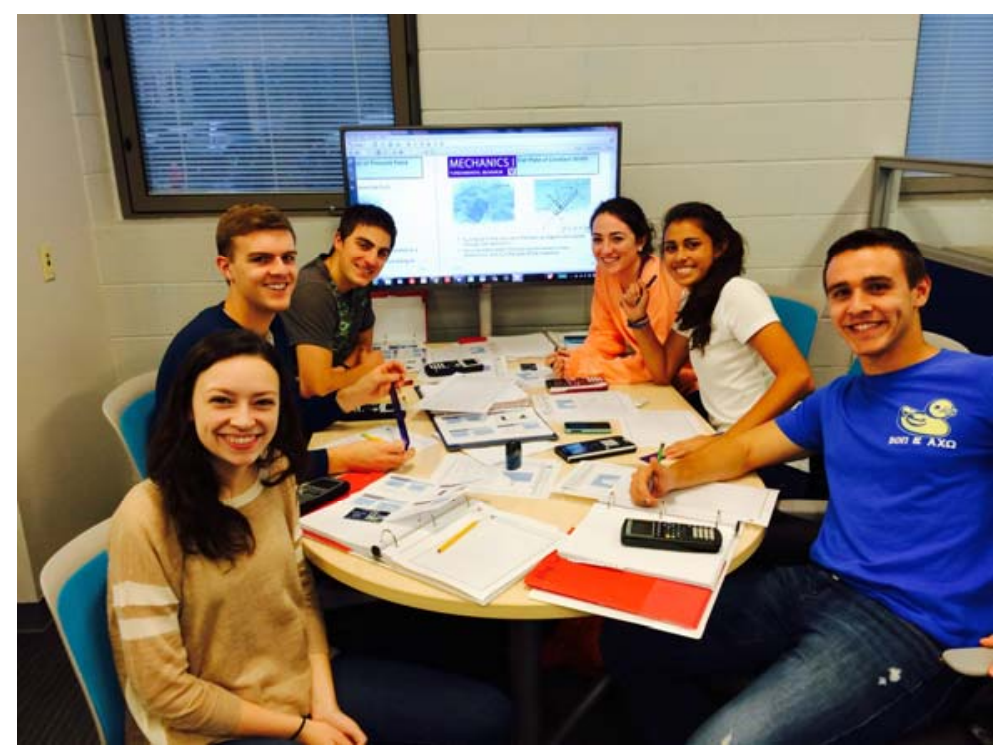

Figure 7 - Closeup of Student Work Area in Interactive Learning Classroom 
Table 5 - Calculation steps within the joist analysis exercise

\begin{tabular}{|c|c|c|}
\hline Step & Calculation task & Questions to be answered \\
\hline 1 & $\begin{array}{l}\text { Compute Member } \\
\text { Forces for a an } \\
\text { Arbitrary (Unit) } \\
\text { Loading }\end{array}$ & $\begin{array}{l}\text { - Which member has the largest tension force and what is the } \\
\text { magnitude of this force? } \\
\text { - Which member has the largest compression force and what is } \\
\text { the magnitude of this force? }\end{array}$ \\
\hline 2 & $\begin{array}{l}\text { Compute Member } \\
\text { Stresses }\end{array}$ & $\begin{array}{l}\text { - Which member has the largest tensile stress and what is the } \\
\text { magnitude of this stress? } \\
\text { - Which member has the largest compressive stress and what } \\
\text { is the magnitude of this stress? }\end{array}$ \\
\hline 3 & $\begin{array}{l}\text { Compute } \\
\text { Allowable } \\
\text { Stresses } \\
\end{array}$ & $\begin{array}{l}\text { - What is the allowable stress for the steel in tension? } \\
\text { - What is the allowable stress for the steel in compression? }\end{array}$ \\
\hline 4 & $\begin{array}{l}\text { Compute Design } \\
\text { Stress Ratios }\end{array}$ & $\begin{array}{l}\text { - Which member controls the design? } \\
\text { - What is the maximum load P that may be applied to the } \\
\text { joints without exceeding the allowable stress values in any } \\
\text { member? }\end{array}$ \\
\hline 5 & $\begin{array}{l}\text { Compute Failure } \\
\text { Stress Ratios }\end{array}$ & $\begin{array}{l}\text { - Which member is expected to fail first? } \\
\text { - What is the load P at which we would expect the first } \\
\text { member to fail? }\end{array}$ \\
\hline
\end{tabular}

\begin{tabular}{|c|c|c|c|c|c|c|c|c|c|}
\hline \multicolumn{10}{|l|}{ Input: } \\
\hline $\mathbf{P}(\mathbf{k})=$ & 1.000 & kip & & & & & & & \\
\hline \multicolumn{10}{|c|}{ SUMMARY OF ANALYSIS CALCULATIONS } \\
\hline Member & $\begin{array}{l}\text { Force } \\
\text { (kips) }\end{array}$ & Tor $\mathrm{C}$ & $\begin{array}{l}\text { Area } \\
\text { (in. }{ }^{2} \text { ) }\end{array}$ & $\begin{array}{l}\sigma_{\text {actual }} \\
(\text { (ksi) }\end{array}$ & $\begin{array}{l}\sigma_{\text {tailure }} \\
\text { (ksi) }\end{array}$ & F.S. design & $\begin{array}{c}\sigma_{\text {allowable }} \\
(\mathbf{k s i})\end{array}$ & $\begin{array}{c}\text { Design } \\
\text { Stress Ratio }\end{array}$ & $\begin{array}{c}\text { Failure } \\
\text { Stress Ratio }\end{array}$ \\
\hline $\mathrm{T} 1 / \mathrm{T} 8$ & 6.989 & C & 0.630 & 11.09 & 30.00 & 1.85 & 16.22 & 0.684 & 0.370 \\
\hline $\mathrm{T} 2 / \mathrm{T} 7$ & 6.393 & $\mathrm{C}$ & 0.630 & 10.15 & 30.00 & 1.85 & 16.22 & 0.626 & 0.338 \\
\hline $\mathrm{T} 3 / \mathrm{T} 6$ & 10.067 & C & 0.630 & 15.98 & 30.00 & 1.85 & 16.22 & 0.985 & 0.533 \\
\hline T4/T5 & 10.067 & C & 0.630 & 15.98 & 30.00 & 1.85 & 16.22 & 0.985 & 0.533 \\
\hline B1/B3 & 8.069 & $T$ & 0.630 & 12.81 & 50.00 & 1.60 & 31.25 & 0.410 & 0.256 \\
\hline B2 & 10.734 & $T$ & 0.630 & 17.04 & 50.00 & 1.60 & 31.25 & 0.545 & 0.341 \\
\hline $\begin{array}{l}\text { P1/P8 } \\
\end{array}$ & 7.817 & $T$ & 0.261 & 29.95 & 50.00 & 1.60 & 31.25 & 0.958 & 0.599 \\
\hline P2/P7 & 3.005 & C & 0.261 & 11.51 & 30.00 & 1.85 & 16.22 & 0.710 & 0.384 \\
\hline P3/P6 & 2.500 & $T$ & 0.261 & 9.58 & 50.00 & 1.60 & 31.25 & 0.307 & 0.192 \\
\hline P4/P5 & 0.833 & C & 0.261 & 3.19 & 30.00 & 1.85 & 16.22 & 0.197 & 0.106 \\
\hline $\mathrm{S} 1 / \mathrm{S} 4$ & 1.164 & C & 0.261 & 4.46 & 30.00 & 1.85 & 16.22 & 0.275 & 0.149 \\
\hline S2/S3 & 1.000 & C & 0.206 & 4.85 & 30.00 & 1.85 & 16.22 & 0.299 & 0.162 \\
\hline
\end{tabular}

Figure 8 - Spreadsheet-Based Table Used to Show Answers During Calculation Period 
The joist geometry and numerical parameters used by students in the analysis were chosen by the instructors to provide specific results that maximize educational benefits. Material failure stresses are established to be different values for tension and compression members, though they are not varied as a function of member length for compression members. This simple approach allows for a brief qualitative discussion about the differences between tension- and compressionrelated member behavior, since students have not yet learned about Euler buckling.

Furthermore, a higher factory of safety is used for compression members than for tension members to reflect the higher potential variability associated with stability calculations as compared to tensile material strength. The numerical values used in the exercise lead students to the "correct" results when the joist is tested in the laboratory. The values also allow for different respective members to have the highest design stress ratios and failure stress ratios. That is, the member that controls the design based on allowable stresses is not the member that is predicted to actually fail first.

After all of the calculation steps are completed, the entire class walks to the Structural Engineering Teaching and Research Laboratory, SETRL. Before testing, the instructors introduce the students to the hydraulic loading equipment, instrumentation, and data acquisition used for the test. Testing of the joist, which can be seen in Figure 9, usually takes about the last ten minutes of the 150-minute class period.

As noted previously, students correctly predict the member that "fails" first. This primary failure is associated with a limit state of tension member yielding (which the students observe as the lime wash on the member flakes off), which is ductile and allows for enough of a redistribution of forces that a secondary failure occurs with buckling of a segment of the top chord in compression. This failure sequence provides an excellent opportunity for the instructors to introduce the concept of ductile material behavior, which is introduced formally in class only a few meetings after this exercise. Similarly, the load at which the primary tension member yielding occurs is typically under predicted by about 15 to $20 \%$ by the student calculations. This provides an example which the instructors can draw upon a few periods later in the course when material properties of steel are introduced, as it illustrates that the specified design yield strength of steel is a probabilistic lower bound value that is usually exceeded by a comfortable margin.

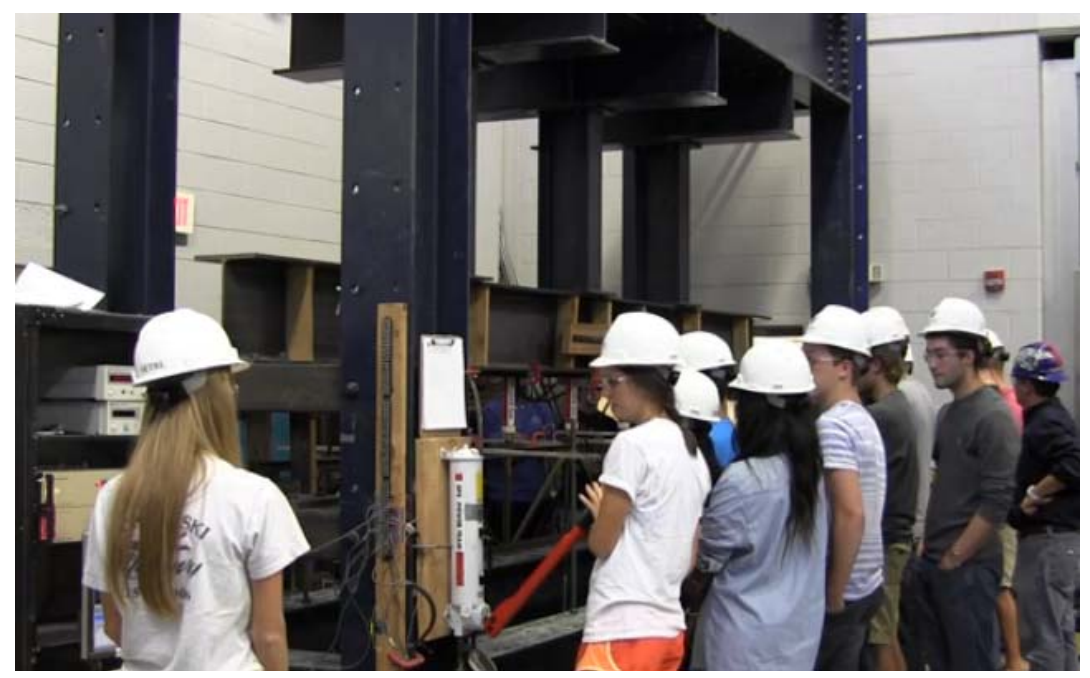

Figure 9 - Joist Being Tested in Laboratory at End of Flex Period 
Flex Period \#8: Coefficients of Friction and Design of Experiments

The eighth flex period is used for a friction-based laboratory exercise in which students are given a scenario where they are required to determine the coefficients of static and kinetic friction between brick pavers and a wood underlayment that will be used in the construction of a sidewalk on a small slope at a local shopping center. Students work in groups on this assignment and must develop their own experiment to determine the requested parameters.

In the two lecture periods preceding this exercise, students learn about friction and apply it in classic statics and dynamics problems such as the blocks sliding (or not sliding) down a ramp. Students solve impending motion problems, as well as problems involving simple kinematics and the equation of motion (these are the only dynamics concepts addressed in Mechanics I). As with most problems solved in the course, the problems solved in these two preceding periods involve specific numerical values.

To assist the students in developing an experimental procedure and to allow for most of the time in the flex period to be spent conducting the experiments, a symbolic solution of the block on a ramp problem is provided as part of the handout for this flex period. The graphic used in the development of equations for the coefficients of static and kinetic friction is shown in Figure 10. Students can utilize this graphic and the equations developed from it in identifying dependent and independent variables for their experimental analysis.

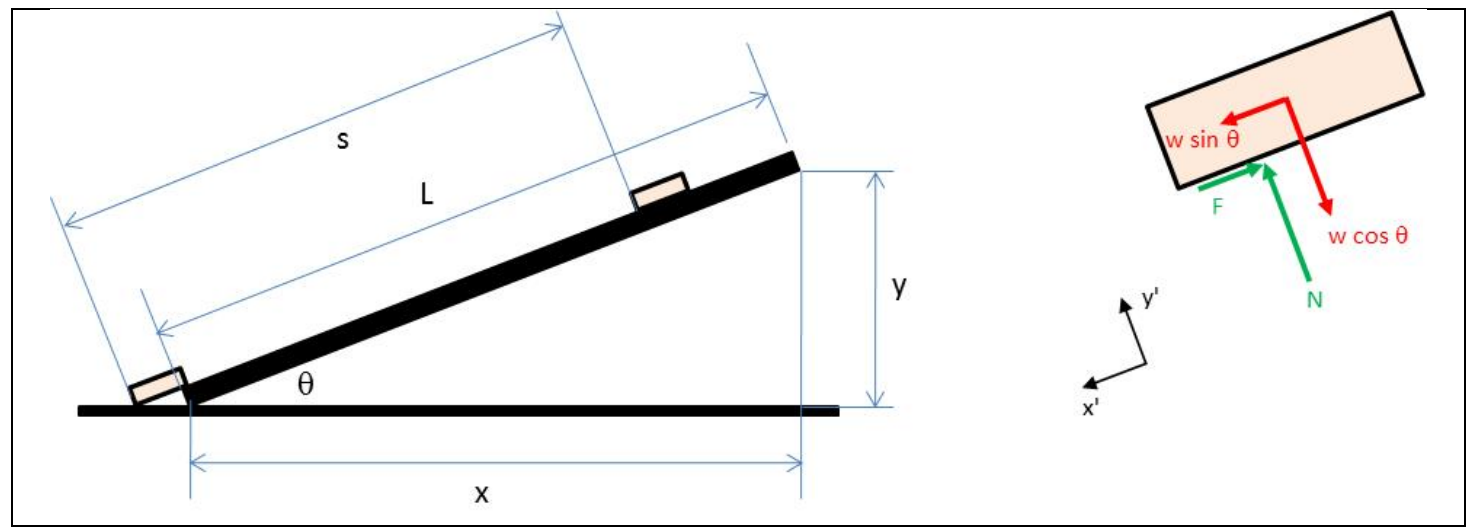

Figure 10 - Graphic used in development of symbolic equations for coefficients of friction

The handout for the problem leads all of the students to a pair of straightforward experimental concepts. To determine the coefficient of static friction, they must determine the position (angle) of the ramp at which the block (brick) begins to slide. To determine the coefficient of kinetic friction, they must determine the time it takes the block (brick) to slide a certain distance down the ramp.

The entire flex meeting takes place in the SETRL. Each student group is given a wood ramp and a measuring tape. They are permitted to use a smartphone for time measurements and a computer (Excel) for assembling and manipulating collected data. The entire class has access to a set of 30 numbered bricks as shown in Figure 11, which may be used for conducting experimental trials. 


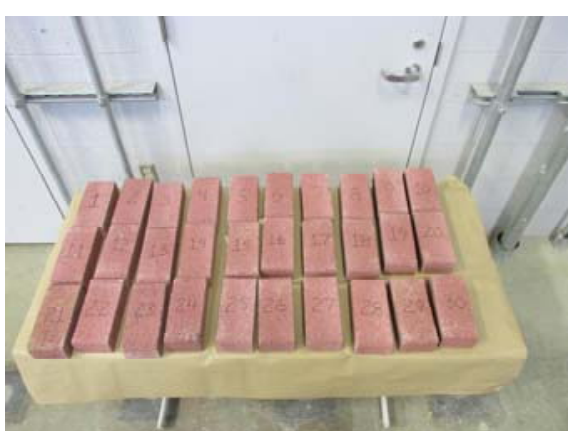

Figure 11 - Set of numbered bricks for friction laboratory exercise

Students are not given any specific requirements or guidance on how many trials to run, how to collect data to ensure the best possible accuracy, or on any other element of the experimental design. Students must work as a group to make these decisions and develop a specific procedure. As students conduct the tests, they generally recognize that the experiment is easy in concept, but that numerous factors that they had never considered may influence their results such as the orientation of the brick, which side of the brick is tested, how timing is synchronized to the release of a brick, etc. During the exercise, the instructors walk around the laboratory and engage with each group to discuss some of these factors and answer other questions. Photos from this laboratory exercise may be seen in Figures 12 and 13.

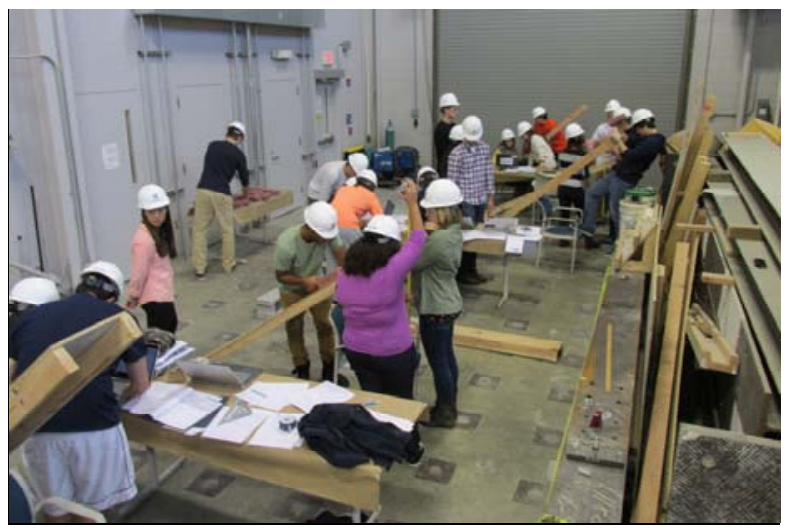

Figure 12 - Student groups working on friction laboratory exercise

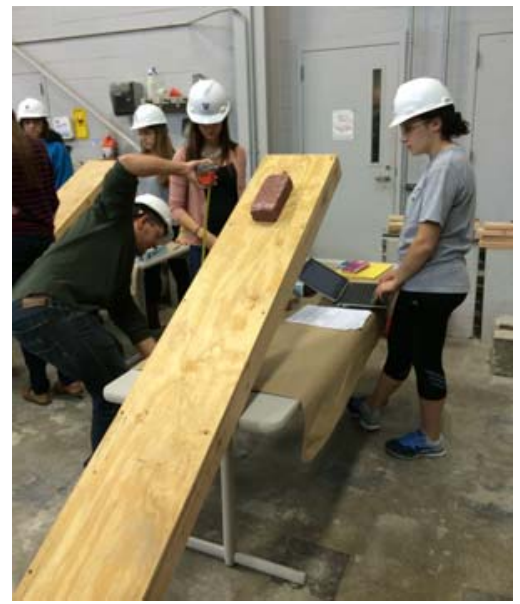

Figure 13 - Student group conducting coefficient of static friction experiment 
Students are also required to implement basic statistics calculations for whatever data they collect. They must report three values for each coefficient of friction: the sample mean, the sample standard deviation, and the 95\% lower confidence limit of the mean. As part of their group assignment submission, students are required to submit neatly prepared datasheets for each test, and answer the eight questions shown below:

1. For the coefficient of static friction, report the sample mean, sample standard deviation, and $95 \%$ lower confidence value of the mean.

2. For the coefficient of kinetic friction, report the sample mean, sample standard deviation, and $95 \%$ lower confidence value of the mean.

3. Provide a detailed, step-by-step test procedure.

4. How many different samples of brick did you decide to test? Why?

5. How did you decide which bricks to test? Why?

6. How many different trials did you perform for each sample? Why?

7. Clearly identify the control variables used for each test. If there were any difficulties keeping these variables constant, note what the difficulties were.

8. Describe the level of accuracy to which you were able to measure the measured variables in each test. What steps did you take, if any, to maximize this accuracy?

\section{Student Feedback}

The Thursday flex periods are well received by students overall. Responses from student surveys indicate that students feel very engaged in these periods and like the way that they are used to tie multiple concepts together with real applications. Most students indicate that they feel the periods are time well spent. Negative comments on the flex periods, though less common, generally relate to the length of the period being too long, or students being exhausted at the end of the period.

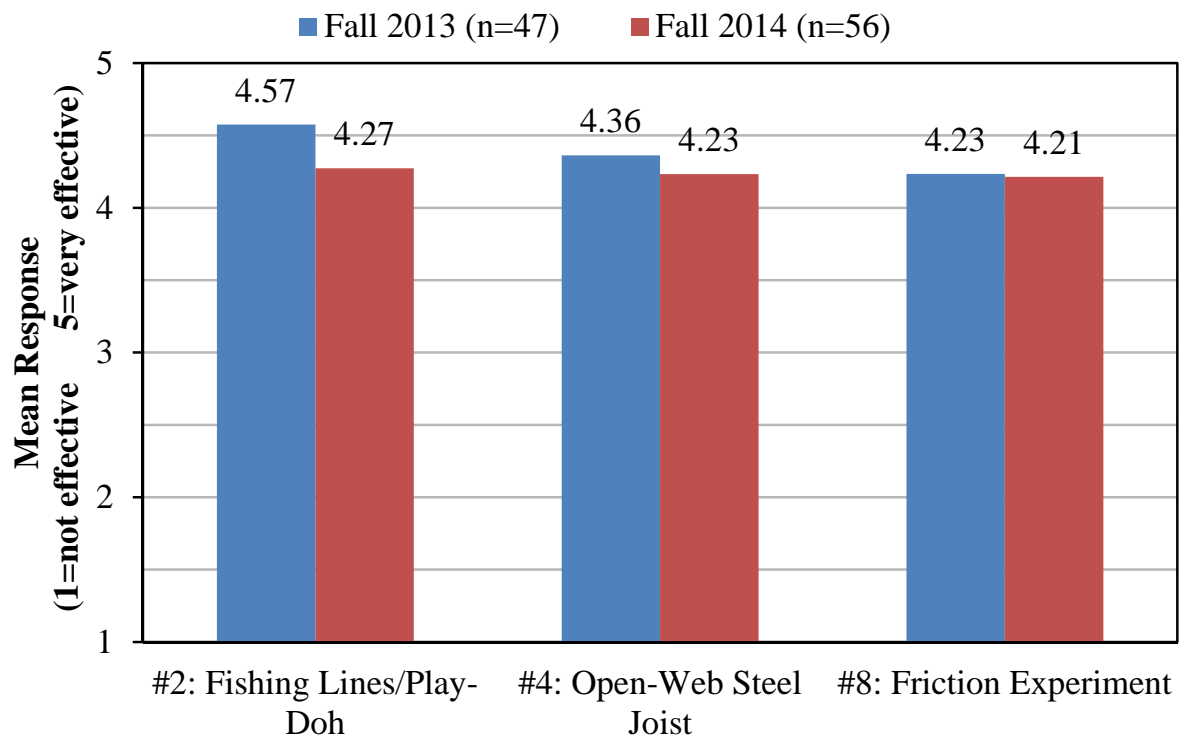

Figure 14 - Responses from student survey on the three flex periods discussed in this paper 
Figure 14 summarizes student feedback on the three flex periods discussed in detail in this paper. Feedback is from an end-of-semester survey given in the Fall 2013 and Fall 2014 semesters. Students were asked how well each of the flex periods contributed to their overall learning in the course on a scale of 1 to 5 , with 1 representing "not effective" and 5 representing "very effective”. Mean responses ranged from 4.21 to 4.57, indicating that students thought the periods were very effective in contributing to their learning. These results are typical of the results for all eleven non-exam flex periods.

\section{Administrative and Other Considerations}

The three flex periods described in detail in this paper do not require the typical section size of approximately 25 to 35 students to be further split to maintain an active learning environment. However, certain flex periods are split such that smaller student groups are able to conduct specific experiments or tests with specific equipment in the classrooms or laboratories. In particular, Flex Periods \#1 and \#6 identified in Table 3 require students to be split into smaller groups based on space and equipment limitations. Each student spends about 75 minutes in class during these particular periods, as sections are subdivided into two subsections of no more than approximately 16 students each. Students are present for nearly the full 165 minutes of the flex period in all cases except these two periods with subdivided groups and the three flex periods used for examinations.

The restructuring of the mechanics course sequence to allow for the flex periods and the accompanied improved learning required an investment of additional faculty resources. At Villanova University, the normal teaching load is 9 contact hours $(\mathrm{CH})$ per semester for tenured and tenured track faculty with three years or more of credit towards tenure. Additionally, section sizes are limited to less than 35 students, so given a normal enrollment of 60 students per year, two sections of all required courses and laboratories must be offered.

Each Mechanics (I, II, or III) course would require a minimum of $12 \mathrm{CH}$ for the two sections if there were no co-teaching employed. However, the authors feel that co-teaching is essential, especially with a flex period of approximately 30 students. With lower enrollments it may not be necessary to have two instructors present for the flex periods. Currently flexible periods are staffed with two faculty members, bringing the total $\mathrm{CH}$ to 18 , the full equivalent load for two faculty members for a semester. The administrative desires to be more efficient in the delivery of course content and more critical of $\mathrm{CH}$ accounting continue to be a real constraint. Moving forward there is a likelihood of allocating $15 \mathrm{CH}$ to be split between the two instructors.

The Department Chair critically reviews the student evaluations from these courses to ensure that the investment of the faculty contact hours is worth the additional resources. As noted within, additional assessments are conducted in these courses, which allows for additional scrutiny of the cost and benefits of additional faculty time. Since the inception of these courses, the data is clear that the invested resources are paying dividends. Mechanics I is consistently the top rated course in the department in terms of student satisfaction. Based on Course And Teacher Surveys (CATS) of students, it is always ranked in the top quartile of the department in effective use of class time, faculty response to student questions, encouraged student questions, relevant assignments, level of learning, quality instruction, and overall value of course. The CATS also 
show that the workload is significant, as the course is also in the top quartile for hours of work per week for students.

To implement the flexible period strategy in an environment where co-teaching is not an option, it may be possible to employee teaching assistants. At larger engineering schools where introductory mechanics courses are taught in large lecture hall formats it may be cost effective employ well-trained teaching assistants to teach/run the flexible periods similar to a recitation format. Obviously, co-teachers working with small section sizes is the optimum learning environment.

The experimental work done in the flex periods is generally conducted using standard equipment maintained by the department in the Structural Engineering Teaching and Research Laboratory. No additional equipment of any significant size or cost was purchased specifically for the development of this course. Some smaller-scale pieces, such as the loading rig shown in Figure 2 and the friction ramps shown in Figures 12 and 13 were built specifically for the course, but these did not require significant time or monetary resources. Most consumables are very inexpensive and as noted previously, the instructors were fortunate to have the open-web steel joists for Flex Period \#4 donated by New Millennium Building Systems.

\section{Conclusion}

The 165-minute flexible or "flex" period is the cornerstone of the revised mechanics course structure in the Department of Civil and Environmental Engineering at Villanova University. A flex period allows for several different teaching and learning strategies that would not be possible in the shorter periods. These periods are specifically designed to be active learning sessions, which allow for better integration of individual concepts to attain a higher level of application. Detailed examples of flex period group exercises presented in this paper highlighted how the flex periods are used for combined analytical and laboratory-type experiences that extend far beyond simple single-concept problems found in most textbooks. Responses from two years of student surveys indicate that students feel very engaged in these flexible periods and value how multiple concepts are brought together with real applications. The inclusion of co-taught flex periods comes at an administrative cost as additional faculty time is required. To date, the College and Departmental administration feel the benefits more than justify the costs.

\section{Bibliography}

1. Glynn, E.F., Dinehart, D.W., Gross, S.P., Hampton, F.P., and Wadzuk, B.M. (2007), “Teaching Engineering Mechanics in a Problem-Structured Environment," Proceedings of the Fall 2007 ASEE Middle Atlantic Section Conference, Philadelphia, PA.

2. Wadzuk, B.M., Dinehart, D.W., Glynn, E.F., Gross, S.P., and Hampton, F.P. (2008), "'Survey of Engineering Mechanics in Civil Engineering Curricula'," Proceedings of the 2008 ASEE Annual Conference and Exposition, Pittsburgh, PA.

3. Dinehart, D.W., Glynn, E.F., Gross, S.P., Hampton, F.P., and Wadzuk, B.W. (2009), “A Methodology for Undergraduate Curriculum Modification," Proceedings of the 2009 ASEE Annual Conference and Exposition, Austin, TX. 
4. Mills, J.E. and Treagus, D.F. (2003) "Engineering Education, Is Problem-Based or Project-Based Learning the Answer?” Australian Journal of Engineering Education.

5. Perrenet, J., Bouhuijs, P., and Smits, J. (2000) "The Suitability of Problem-Based Learning for Engineering Education: Theory and Practice," Teaching in Higher Education, Vol. 5. No. 3.

6. Mays, T., Bower, K., Settle, K., and Mitchell, B. (2007) "Using Concept-Oriented Example Problems to Improve Student Performacne in a Traditional Dynamics Course,” Proceedings of the 2007 ASEE Annual Conference \& Exposition, Austin, TX.

7. Graaf, E.D. and Kolmos, A. (2003) “Characteristics of Problem-Based Learning,” International Journal of Engineering Education, Vol. 19, No. 5.

8. Hake, R.R. (1997) "Interactive-Engagement vs. Traditional Methods: A Six-Thousand-Student Survey of Mechanics Test Data for Introductory Physics Courses,” American Journal of Physics, Vol. 66.

9. Sahin, M. (2010) "The Impact of Problem-Based Learning on Engineering Students' Beliefs About Physics and Conceptual Understanding of Energy and Momentum," European Journal of Engineering Education, Vol. 35, No. 5.

10. Albanese, M.A. and Mitchell, S. (1993) "Problem-Based Learning: A Review of Literature on Its Outcomes and Implementation Issues," Academic Medicine, Vol. 68.

11. Yaeger, P.M., Marra, R.M., Gray, M.G.L., and Costanzo, F. (1999) “Assessing New Ways of Teaching Dynamics: An Ongoing Program to Improve Teaching, Learning, and Assessment," Proceedings of the 1999 ASEE Annual Conference \& Exposition, Charlotte, NC.

12. Barell, J. (1998) “Problem Based Learning, an Inquiry Approach”, Hawker Brownlow Education, Australia.

13. http://www.bme.gatech.edu/pbl/

14. Jarvis, A.P. and Quick, N.J. (1992) “The Integration of Design and Manufacture, a Project Based Approach to Learning," $3^{\text {rd }}$ World Conference on Engineering Learning, Vol. 3, Portsmouth, UK.

15. Woods, D. R. (1996) “Problem-Based Learning for Large Classes in Chemical Engineering,” New Directions for Teaching and Learning, Vol. 1996, No.68.

16. Kellar, J.J., Hovey, W., Langerman, M., Howard, S., Simonson, L., Kjerengtroen, L., Sttler, L., Heilhecker, H., Ameson-Meyer, L., and Kellogg, S.D. (2000) "A Problem Based Learning Approach for Freshman Engineering," $30^{\text {th }}$ Annual Frontiers in Education, Vol. 2.

17. Klosky, J. Hains, D., Johnson, T. Bruhl, J., Erickson, J.B., and Richards, J. (2007) “An Integrated Approach for Engineering Mechanics and Design,” Proceedings of the 2007 ASEE Annual Conference \& Exposition, Austin, TX.

18. O'Neill, R., Geiger, R. C., Csavina, K., and Orndoff, C. (2007) “Making Statics Dynamic! Combining Lecture and Laboratory Into An Interdisciplinary, Problem-Based, Active Learning Environment”, Proceedings of the 114th Annual ASEE Conference and Exposition, June.

19. Hall, D., Hadala, P., and Roberts, F. (2000) "Laboratory Exercises for Statics and Mechanics of Materials on a Shoestring”, Proceedings of the ASEE Annual Conference, June. 
20. Kaul, S. and Sitaram, P. (2013) “Curriculum Design Of Statics And Dynamics: An Integrated Scaffolding And Hands-On Approach”, Proceedings of the 120th ASEE Annual Conference, June.

21. Dodge, R. E., Fisher, B. C., King, J. J., Kuehl, P. G., Matsuki, S., Mitchell, W. E., Dailey, J. F., and Boyajian, D. M. (2011) "Introducing the Structural Engineering Encounter Laboratory: A Physical Approach to Teaching Statics, Mechanics of Materials and Structural Analysis” World Transactions on Engineering and Technology Education, v 9, n 2.

22. Campbell, I. (2004) “The Use of Model Making (and Breaking) in Freshman Engineering Statics Courses”, Proceedings of the ASEE Annual Conference, June.

23. Gross, S.P., Dinehart, D.W., Yost, J.R., and Radlinska, A. (2011) "Overarching Problems in Sophomore Mechanics Courses", Proceedings of the 2011 American Society of Engineering Educators Annual Conference and Exposition, June. 